\title{
SUPERPLASTIC DEFORMATION OF THE AK4-1 ALLOY WITH A SURFACE LAYER MELTED BY ELECTRON PULSE BEAM
}

\author{
V.V. Bryukhovetsky ${ }^{1}$, A.V. Poyda ${ }^{1}$, V.P. Poyda ${ }^{2}$, D.E. Milaya ${ }^{1,2}$ \\ ${ }^{1}$ Institute of Electrophysics and Radiating Technologies NAS of Ukraine, Kharkov, Ukraine \\ E-mail: ntcefo@yahoo.com; \\ ${ }^{2}$ V.N. Karazin Kharkiv National University, Kharkov, Ukraine \\ E-mail: postmaster@univer.kharkov.ua
}

Specimens of the aluminum alloy AK4-1, previously irradiated by a pulsed electron beam, are deformed under the conditions of superplasticity. The features of structural changes in the course of superplastic deformation of preirradiated specimens are studied. It is shown that the deformation processes occurring in the main part of the specimen and in the layer, melted by a pulsed electron beam, have fundamental differences.

\section{INTRODUCTION}

The vast majority of modern constructional and tool materials are produced with hardened working surfaces or applied coatings. The properties of the surface metal interlayers very often play a decisive role in maintaining the performance characteristics of the alloys in terms of their use as structural materials and parts of mechanisms. However, increasing, thus, the operational resource of materials significantly reduces their plasticity, since stress concentrators arise at the interfaces between materials. The failure of the material most often begins from the surface. Therefore, the study of the deformational mechanisms of materials with reinforcing coatings or surface-hardened layers is of great practical and scientific interest.

In the case of constructional aluminum alloys, special surface layers forms as a result of their hot rolling. Also, as a special surface layer may be the presence of a cladding layer of technically pure aluminum. One of the promising methods of modifying the surface of materials is electrophysical radiation processing. Processing by a pulsed beam of relativistic electrons leads to a change in the physical and chemical properties of the surface layer of the material, which is often used to obtain hardening and protective coatings [1]. The structure and properties of the thus obtained layers were previously studied in a number of papers [25]. In this work, specimens of heat-resistant industrial aluminum alloy AK4-1 were subjected to this kind of irradiation.

From the point of view of physical mesomechanics, the deformation processes in the surface layers and the volume of the material develop, although correlated, but autonomously at all stages [6]. At the same time, it is analytically shown in [7] that the coating of a lowplastic metal by a layer with high plastic properties leads to an increase in the plasticity of such a composite. Proper understanding of the behavior of the surface layers of material during superplastic deformation is important when developing technologies for deforming materials under superplasticity conditions. Various aspects of the behavior of surface layers during superplastic deformation have already been investigated previously in a number of works [8-10]. In this work, we studied behavior of the surface layer of specimens of heat-resistant aluminum alloy AK4-1 under the conditions of superplastic deformation. In this case, the surface layer in this alloy was created by irradiating of the specimens by a pulsed electron beam. Such studies are very important both for a deeper understanding of the physical nature of the superplasticity effect, and for the possibility of applying technologies of superplastic forming to materials whose surface is processed by pulsed energy action.

\section{MATERIAL AND EXPERIMENTAL}

Alloy AK4-1 (another designation - alloy 1141) has the following chemical composition: $\mathrm{Al}$; $2.0 \ldots 2.6$ wt. $\% \mathrm{Cu} ; 1.2 \ldots 1.8$ wt.\% Mg; $0.9 \ldots 1.4$ wt.\% Fe; 0.9..1.4 wt.\% Ni; 0.1..0.25 wt.\% Si; $0.05 \ldots 0.1$ wt.\% Ti; $0.1 \mathrm{wt} . \% \mathrm{Mn} ; 0.1 \mathrm{wt} . \% \mathrm{Zn}$ [11]. This alloy is one of the deformable by pressure alloys and is widely used in mechanical engineering and aircraft construction. Due to the presence of iron and nickel in the composition of the alloy AK4-1, this alloy is also heat resistant. Irradiation of alloys' plates were performed by a high-current pulsed beam of relativistic electrons at the MIG-1 accelerator in the NSC KIPT NAS of Ukraine [1]. The energy flux density at the target $\mathrm{W}$ is approximately $109 \mathrm{~W} / \mathrm{cm}^{2}$ (beam energy $\mathrm{E} \sim 0.3 \mathrm{MeV}$, current $\mathrm{I} \sim 2000 \mathrm{~A}$, pulse duration $\tau_{\mathrm{i}} \sim 5 \cdot 10^{-6} \mathrm{~s}$, beam diameter $\mathrm{D} \sim 3 \mathrm{~cm}$ ).

The prismatic specimens cut from the industrial semi-finished product of the alloy AK4-1 along the rolling direction had the following working section dimensions: $2.0 \times 4.5 \times 10 \mathrm{~mm}$. Mechanical tensile tests of the specimens were performed in air in creep mode at a constant flow stress. Creep curves were recorded automatically using the electronic recorder EPP-09. They were rebuilt in the coordinates of the true deformation - time. The true strain rate $\dot{\varepsilon}$ was determined from creep curves.

Structural studies at various stages of specimens' deformation were carried out using light (MIM-6) and scanning electron microscopy (JEOL JSM-840).

The kinetics of phase transformations occurring in specimens of AK4-1 alloy in the process of heating was investigated on a Derivatograph Q-1550 device. 


\section{RESULTS AND DISCUSSION}

Processing of the products by concentrated energy flows makes it possible to purposefully modify the properties of the surface layers. The use of high-current relativistic electron beams with a power density of up to $10^{9} \mathrm{~W} / \mathrm{cm}^{2}$ for this purpose allows to heat and melt the surface layer to a depth of $100 \mu \mathrm{m}$ quickly and uniformly over a relatively large area [1]. The impact of the electron beam is combined: percussive, thermal and radiational [1-6]. The rapid solidification of the molten layer under the conditions of large temperature gradient and high pressures leads to directional solidification of the melt under non-equilibrium conditions, obtaining nanocrystalline and amorphous structures, redistributing the alloying components of the alloy in the melted layer [2-5]. All this leads to a change in the properties of the near-surface layer.

Fig. 1, a shows a general view of a plate surface made from an AK4-1 alloy sheet, which was irradiated by a pulsed electron beam. It can be seen that the intense heating of the plate produced by the electron beam led to the melting of its surface layer. A general view of the AK4-1 alloy specimen for mechanical testing, which was cut from irradiated plate, is also shown in Fig. 1,a. Fig. 1,b shows the characteristic surface relief of the plates after irradiation. It is seen that the intense heating generated by the action of an electron beam leads to the melting of the surface layer. The thickness of the remelted layer, as can be seen from Fig. 1,c is about $100 \mu \mathrm{m}$. The presence of long cracks, which are branched, indicates the presence of significant internal stresses, which arise in the melted layer at the moment of solidification on the surface (see Fig. 1,b). As can be seen from Fig. 1,c, the cracks spread to the entire depth of the melted layer. Zigzag crack propagation is probably related to the local heterogeneity of the strength and plastic properties of the material in various microvolumes and, in particular, to the local heterogeneity of the distribution of alloying elements in the solidified material or local heterogeneity of the distribution in the near-surface zone of particles of intermetallic phases. Apparently, the relaxation of internal stresses resulting from exposure by radiation on the surface of AK4-1 alloy plate was not fully realized during the crystallization of the melted surface layer, therefore, the remaining internal stresses caused the formation of cracks.

Mechanical tests of initial non-irradiated specimens of this alloy AK4-1 in creep mode at a constant applied flow stress were performed earlier in [12]. Tests were performed at temperatures of $753,773,793,813 \mathrm{~K}$ and a range of flow stresses $\sigma=4.0 \ldots 8.0 \mathrm{MPa}$. The specimens of AK4-1 alloy showed the effect of superplasticity at test temperatures of $773,793,813 \mathrm{~K}$. Therefore, the mechanical tests of the irradiated specimens were performed at these three temperatures.

Fig. 2 shows the graphs of the dependences of elongation to failure $\delta$ from the applied flow stress $\sigma$ for irradiated specimens of alloy AK4-1, deformed to failure at temperatures $773,793,813 \mathrm{~K}$. It can be seen that the dependences of the relative elongation to failure $\delta$ of irradiated specimens of alloy AK4-1 from the applied flow stress $\sigma$ at these test temperatures has a typical for superplasticity view of curves with maximum.
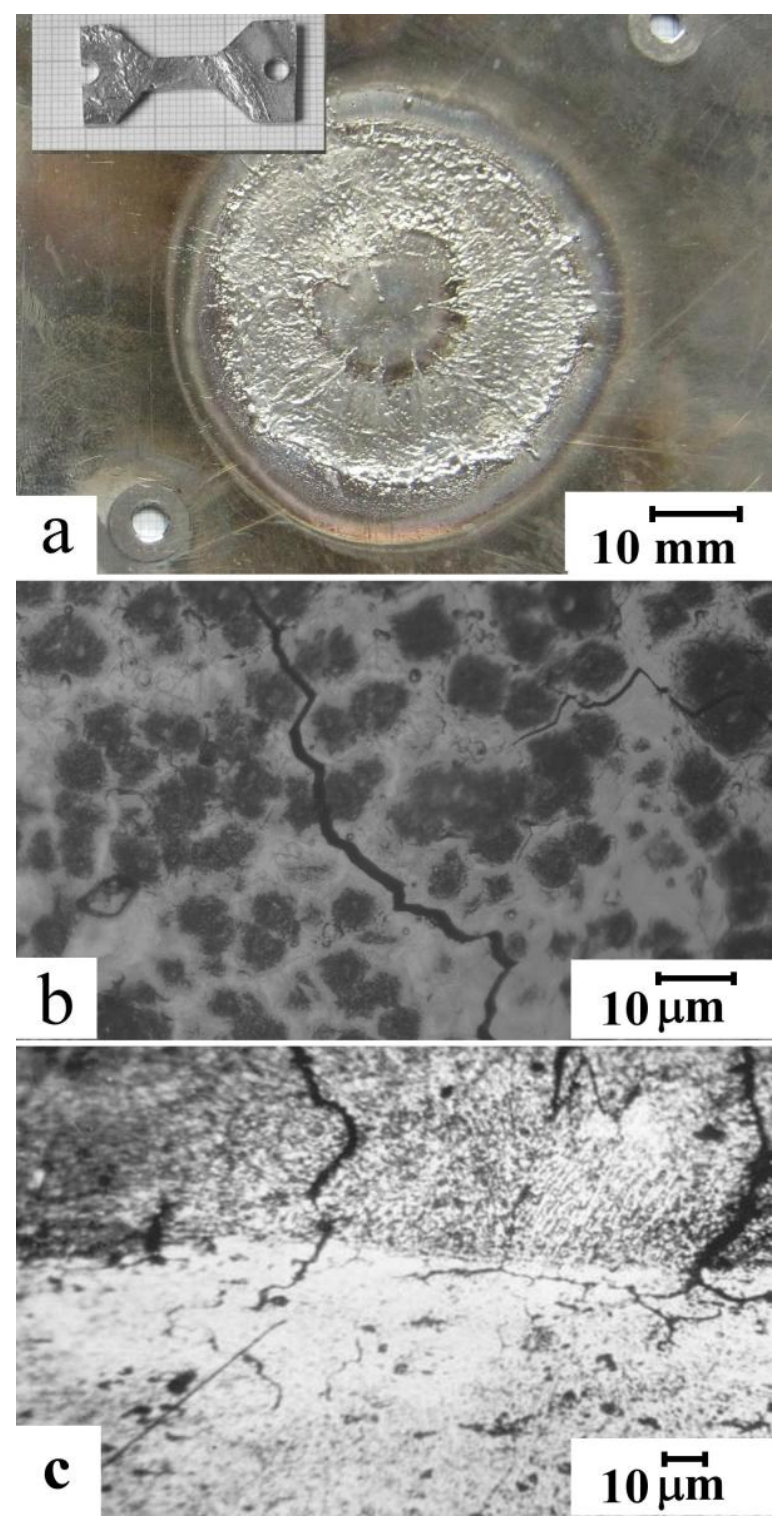

Fig. 1. A general view of the plate surface made from AK4-1 alloy irradiated by a pulsed electron beam and a specimen cut from it for mechanical testing (a);

the characteristic view of the surface fragment of the working part of the alloy AK4-1 specimens (b); microstructure of the alloy AK4-1 in the electron beam processing zone (c)

The results of mechanical tests of irradiated specimens are practically identical with those of the unirradiated specimens performed in [9]. Structural studies, which were performed in [12], led to the conclusion about the implementation of grain boundary sliding under the conditions of superplastic deformation of alloy AK4-1 specimens. The development of this process, in particular, is evidenced by the identification of a developed deformation relief on the previously polished smooth surface of the working part of specimens. 


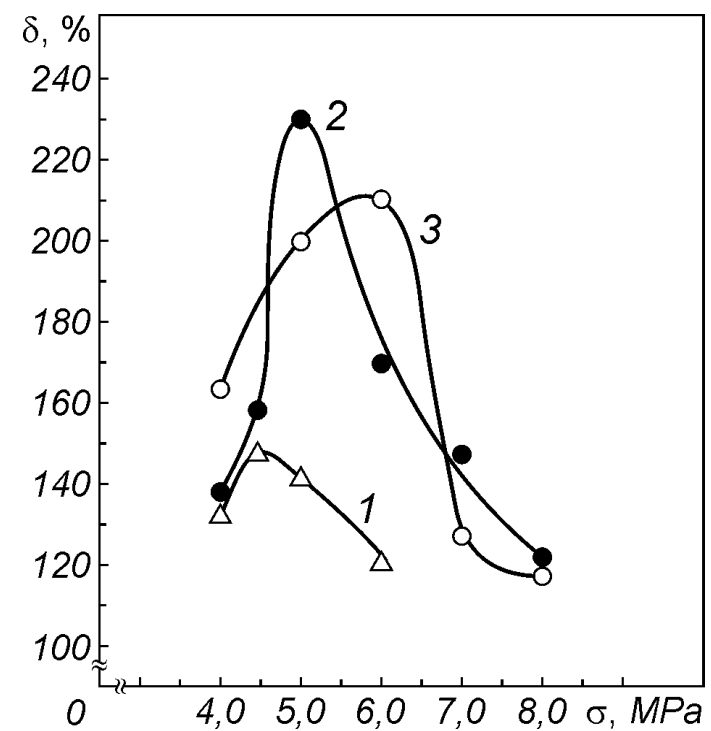

Fig. 2. Dependencies $\delta=f(\sigma)$ for specimens of alloy AK4-1, deformed to failure at:

$T=773 K$ (curve 1$) ; T=793 K($ curve 2$)$; $T=813 K$ (curve 3$)$

Also during deformation of the alloy AK4-1 specimens, the formation of grain-boundary cavities and cracks, as well as breaks in previously applied reference marks, was observed.

Superplastic deformation of the material at elevated temperatures can be described by the following equation [13]:

$$
\dot{\varepsilon}=\frac{\mathrm{ADGb}}{\mathrm{kT}}\left(\frac{\mathrm{b}}{\mathrm{d}}\right)^{\mathrm{p}}\left(\frac{\sigma}{\mathrm{G}}\right)^{\mathrm{n}},
$$

where $\dot{\varepsilon}$ is strain rate; $\mathrm{A}$ is a constant relevant to deformation mechanism; $\mathrm{G}$ is the shear modulus; $\mathrm{T}$ is the absolute temperature; $\mathrm{k}=1.38 \cdot 10^{-23} \mathrm{~J} / \mathrm{K}$ is Boltzmann's constant; $b$ is the Burgers vector; $d$ is the grain size; $p$ is the grain size exponent $(p=0$ for dislocation creep, $\mathrm{p}=2$ for lattice diffusion as the rate controlling mechanism, $\mathrm{p}=3$ for grain boundary controlled flow); $\mathrm{n}(=1 / \mathrm{m})$ is the stress exponent; D is the appropriate diffusion coefficient. The diffusion coefficient $\mathrm{D}$ is defined as $\mathrm{D}=\mathrm{D}_{0} \exp (-\mathrm{Q} / \mathrm{RT})$, where $\mathrm{D}_{0}$ is the preexponent, $\mathrm{Q}$ is the diffusion activation energy and $\mathrm{R}=8.314 \mathrm{~J} \cdot \mathrm{mol}^{-1} \cdot \mathrm{K}^{-1}$ is the gas constant.

According to Eq. (1), the strain rate sensitivity exponents, $m$, can be defined as

$$
m=\frac{d \ln \sigma}{d \ln \dot{\varepsilon}},
$$

Fig. 3 shows variation of flow stress at a true strain of 0.2 as a function of strain rate at different temperatures. The $m$ values vary from 0.35 to 0.53 , indicating that the superplastic mechanism could be a combination of dislocation viscous glide and GBS. The maximum elongation of $230 \%$ is achieved at $793 \mathrm{~K}$ with strain rate of $3.1 \cdot 10^{-4} \mathrm{~s}^{-1}$, corresponding to the maximum $m$-value of 0.53 , which implies that GBS becomes the predominant mechanism of deformation.

Fig. 4 shows a series of images of the working part surface of the alloy AK4-1 specimen. The specimen was pre-irradiated by a pulsed electron beam, and then deformed superplastically to various degrees of deformation. It can be seen that the state of the surface remelted layer after deformation under superplastic conditions differs from the general state of the deformed specimen.

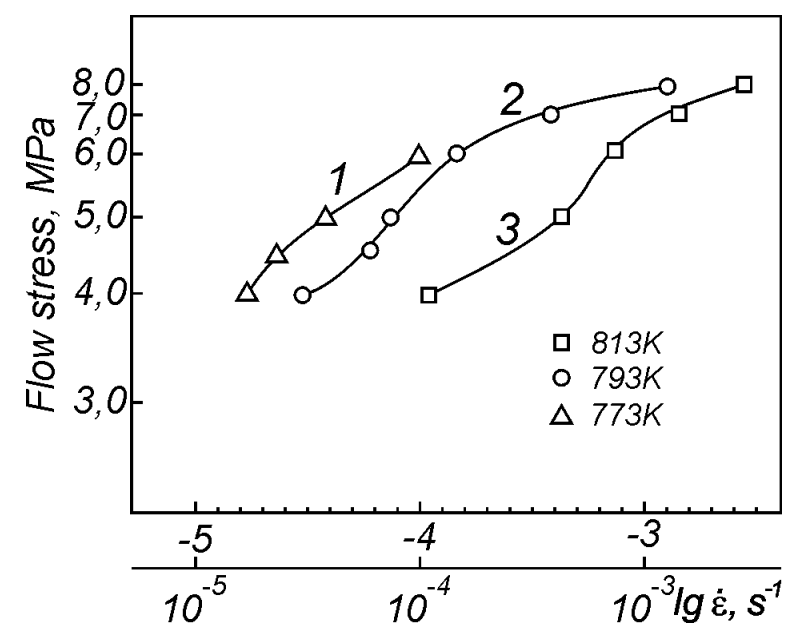

Fig. 3. Dependencies $\lg \sigma=f(\lg \dot{\varepsilon})$ for specimens of alloy AK4-1 deformed at:

$T=773 K$ (curve 1$) ; T=793 K($ curve 2$)$; $T=813 K$ (curve 3 )

The melted layer has multiple fractures and delaminations. Apparently, the fragments of this layer sided along the surface of the part of the specimen that was not melted by the electron beam. That is, the deformation processes occurring in the main part of the specimen and in the layer remelted by a pulsed electron beam are fundamentally different. While the main part of the specimen, considering the data of mechanical tests, deforms superplastically, the surface remelted layer is divided into the nucleated fragments. This is confirmed by a general view of fracture fractogram of deformed irradiated specimen (Fig. 5). According to the fracture fractogram, it can be seen that the thickness of the specimen during the deformation process decreased almost three times. At the same time, the upper modified layer formed as a result of irradiation practically does not decrease in thickness over the time of deformation. Its thickness remained about $100 \mu \mathrm{m}$. It, being divided into fragments, is dispersed on the surface of the deformable part of the specimen. Apparently, only the main non-melted part of the specimen flows superplastically.

As can be seen from Fig. 1,b,c, a number of cracks are already present on the initial irradiated surface. According to [6], under uniaxial tension of a material with hardened surface layer under conditions of ordinary plastic deformation, a strong bending moment develops. This is due to the incompatibility of deformation in the hardened layer and at the base of the strained specimen. The consequence of this is the emergence of concentration of elastic stresses zones and, possibly, the formation of cracks in the surface layer.

Therefore, apparently, during the deformation, the opening of cracks in the surface layer partially proceeds along the cracks already formed during crystallization, and the formation and development of new cracks also occurs. 

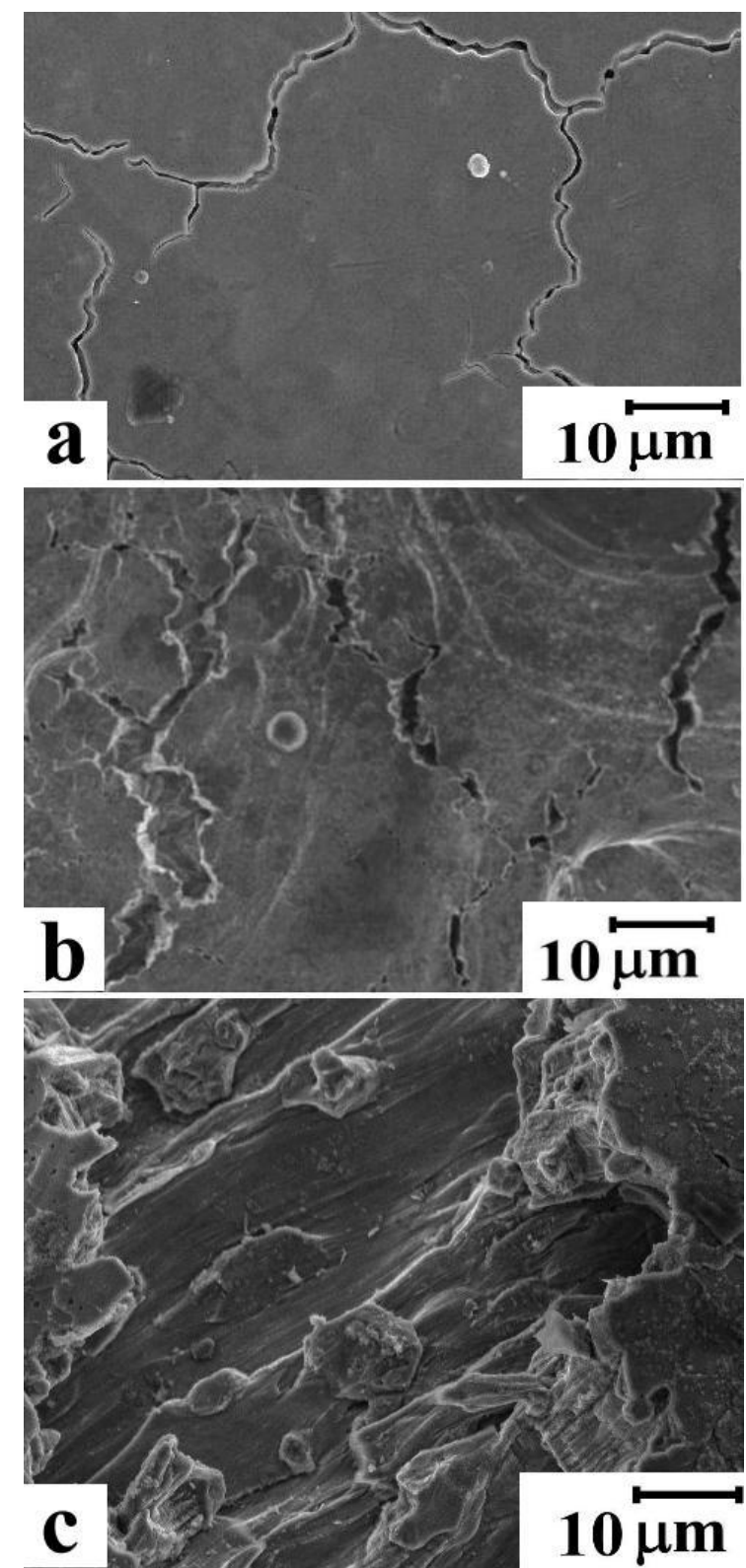

Fig. 4. Different types of the surface of the working part of the AK4-1 alloy specimen, previously irradiated by a pulsed electron beam, and then deformed under superplasticity to various degrees of deformation:

$$
a-15 ; b-50 ; c-260 \%
$$

It should be noted that the formation and development of cracks, also oriented approximately perpendicular to the strain direction, is also observed during superplastic deformation of unirradiated specimens of this alloy.

However, the formation of these surface cracks under the same temperature and strain rate conditions is accompanied by the formation and development of fibrous structures in them (Fig. 6).

The average diameter of such fibers is several micrometers. The length of the fibers correlates with the linear size of the surface cracks in the tension direction and reaches $100 \mu \mathrm{m}$ in the investigated alloy. The formation of such fibers during high-temperature superplastic deformation was observed in many aluminum-based alloys [15-23].

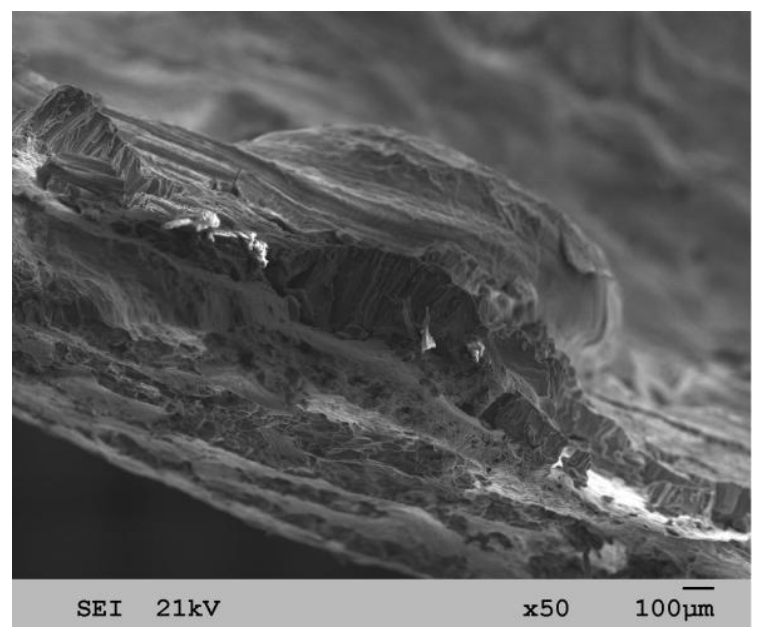

Fig. 5. General view of the irradiated AK4-1 alloy fracture surface superplastically deformed to fracture under the optimal conditions

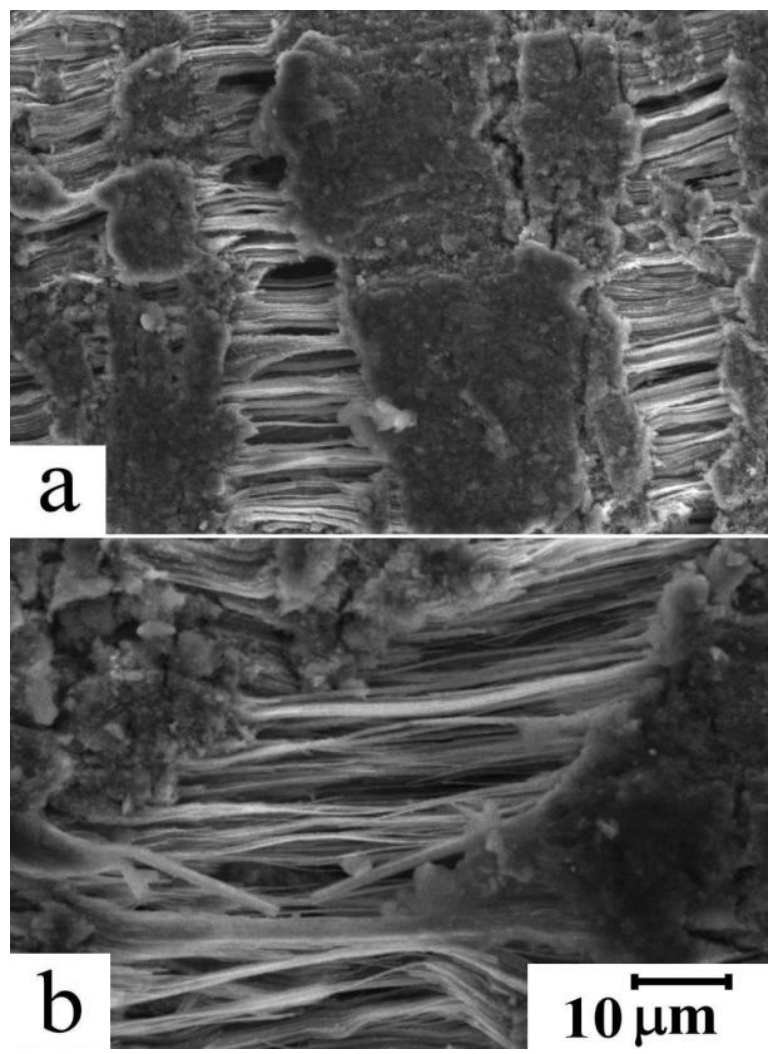

Fig. 6. Types of deformation relief and fibrous formations in the working part of the alloy AK4-1 specimen superplastically deformed to fracture under the optimal conditions to various deformation degrees

The causes of fiber formation and the mechanisms of their development have also been studied in many papers [17-23]. However, all the fiber formation mechanisms discussed in the literature, cannot fully explain their origin [17]. In papers [18-23] the assumptions were put forward and developed that fibers are formed and developed during the opening of cavities and cracks as a result of the viscous flow of a liquidsolid material located at the grain boundaries. Scheme of kinetics of fiber formation and development during the superplastic deformation is developed. It considers case 
than specimens contain at intergranular boundaries areas of viscous liquid phase [21].

Fig. 7 shows the thermogram, obtained as a result of differential thermal analysis of alloy AK4-1 specimen, which was heated from room temperature to a temperature $\mathrm{T}=860{ }^{\circ} \mathrm{C}$ with a heating rate of $5^{\circ} \mathrm{C} / \mathrm{min}$.

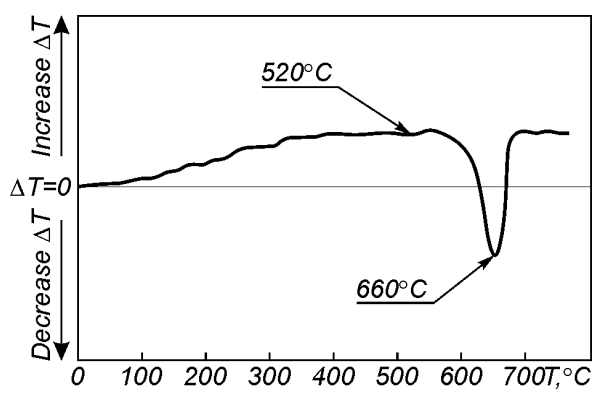

\section{Fig. 7. Curve of differential thermal analysis of the alloy AK4-1 specimen}

It can be seen that in the temperature range $\left(490 \ldots 560^{\circ} \mathrm{C}\right)$, phase transformations take place in its specimens, as a result of which heat is absorbed. I.e. it is likely that the alloy is partially melted.

Mechanical tests of both irradiated and initial alloy specimens were performed at the same temperatures. Thus, during the superplastic deformation of both irradiated and non-irradiated specimens, a liquid phase could be present in their structure. However, fibrous structures were found only in the surface layer of unirradiated alloy specimens. Consequently, in the nearsurface layers of irradiated and unirradiated specimens of alloy AK4-1, the deformation processes developed in different ways. In the case of unirradiated specimens, the separation of grains from each other in the process of grain-boundary sliding led to the development of a viscous flow of a liquid-solid material, which, as a result of partial melting, formed at the grain boundaries. This viscous flow, that is, the manifestation of the so-called "microsuperplasticity" [18], led to the formation and development of fibrous structures. In irradiated specimens in the near-surface remelted layer, the formation of filamentary structures does not occur, on the surface they are actually absent. As is known [2-6], the structure of a layer, remelted by an electron beam is, as a rule, amorphous or nanocrystalline. On the one hand, the creation of a nanocrystalline structural state leads to an increase in strength, but to a decrease in ductility [24]. However, nanocrystalline materials have high rates of superplasticity. In addition, as shown in [9], the surface layer, even from pure aluminum, which does not initially have superplastic properties, can be superplastic in the composition with magnesium alloy. For this purpose, the interlayer must have very strong connection. When the modified surface layer is firmly bound to the base of alloy, the neck formation in the surface layer is suppressed by uniform superplastic deformation of the base part of the specimen [9]. In [9], the connection between the specimen body and surface layer was intermetallic from the $\mathrm{Al}_{3} \mathrm{Mg}_{2}$ phase. However, the mechanical test temperature was much lower than the melting point $\left(\mathrm{T}_{\mathrm{i}}\right)$ of this phase. Therefore, the surface layer was firmly connected to the base of the specimen. In the case of the investigated alloy AK4-1, the surface layer consists of the same material, but it is in a different structural state. Between these two layers there is a separating boundary [2]. However, the temperature of mechanical test has already exceeded certain temperature $\left(\mathrm{T}_{\mathrm{i}}\right)$ at which partial melting of the alloy can occur. And, probably, the zones of elastic stresses arising under the conditions of applied stress relax by sliding of separate surface fragments along the boundary of the layer connection.

Fig. 8 shows a diagram of the development of deformation processes in the modified surface layer under superplasticity conditions. Apparently, above a certain temperature $T_{i}$, at which signs of local melting of the material begin to appear, the surface modified layer will no longer deform superplastically, but will simply slide along the plane of interconnection of the layers, separating into fragments.

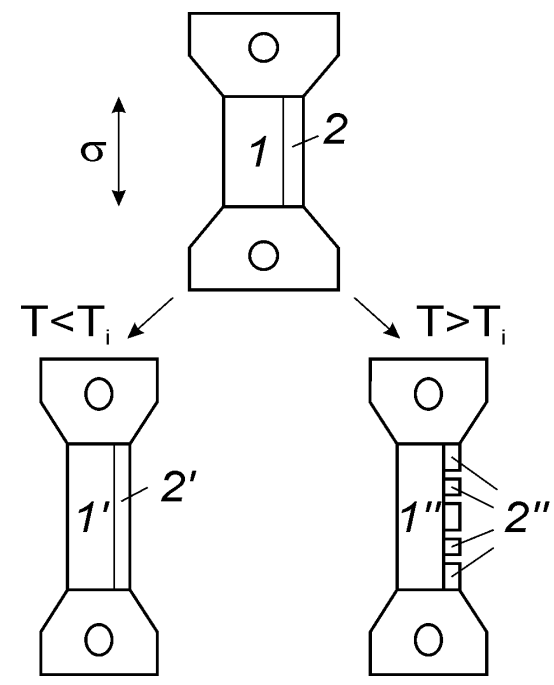

Fig. 8. Schematic representation of the development of deformation processes in the modified surface layer under superplasticity conditions (1 is the base of the alloy, 2 is the modified layer)

\section{CONCLUSIONS}

1. It is determined that the specimens of the alloy AK4-1 exposed to irradiation have phenomenological characteristics typical for superplasticity. The maximum relative elongation of specimens deformed to failure under the superplastic conditions is $230 \%$. At the same time, the presence of a surface layer with a more equiaxed and fine-grained structure does not lead to a significant improvement of the superplastic properties.

2. The state of the surface remelted layer after deformation under the superplasticity conditions differs from the general state of the deformed specimen. The remelted layer has multiple fractures and delaminations. The deformation processes occurring in the main part of the specimen and in the layer remelted by a pulsed electron beam are fundamentally different. While the main part of the specimen, as is clear from the data of mechanical tests, is superplastically deformed, the surface of remelted layer is simply divided into fragments, the boundaries of which are cracks formed after crystallization of the remelted layer. 
3. The state of the boundary between the surface layer and the base of the specimen is of decisive importance for the development of deformation processes in the surface modified layer.

\section{REFERENCES}

1. V.F. Klepikov, Yu.F. Lonin, V.V. Lytvynenko, A.V. Pashenko, A.G. Ponomarev, V.V. Uvarov, V.T. Uvarov, V.I. Sheremet. The formation of strengthening coats by microsecond duration highcurrent relativistic electron beam // Problems of Atomic Science and Technology. Series "Nuclear Physics Investigations". 2008, N 5 (50), p. 91-95.

2. A.G. Kobets, P.R. Horodek, Yu.F. Lonin, V.V. Lytvynenko, A.G. Ponomarev, O.A. Startsev, V.T. Uvarov. Melting effect on high current electron beam on aluminum alloy 1933 // Surface Engineering and Applied Electrochemistry. 2015, v. 51, N 5, p. 478482.

3. V.V. Bryukhovetsky, V.P. Poyda, A.V. Poyda, V.F. Klepikov, D.E. Pedun, Yu.V. Kolomak. The influence of radiation factor on development of deformation processes in superplastic conditions // Problems of Atomic Science and Technology. Series "Physics of Radiation Effect and Radiation Materials Science”. 2012, N 5 (81), p. 3-7.

4. M.I. Bazaleev, V.V. Bryukhovetsky, V.F. Klepikov, V.V. Lytvynenko, A.G. Ponomarev, V.V. Uvarov. The metal surface glasslike melting by the pulse tube like electron beam's influence // Problems of Atomic Science and Technology. Series "Physics of Radiation Effect and Radiation Materials Science”. 2005, N 5, p. 146-149.

5. V.V. Bryukhovetsky, V.V. Litvinenko, V.F. Klepikov, R.I. Kuznetsova, V.P. Poida, V.F. Kivshik, and V.T. Uvarov. Effect of Pulse Electron Irradiation on the Parameters of Duralumin Superplasticity // Fiz. Khim. Obrab. Mater. 2002, N 4, p. 33-38 (in Russian).

6. S.V. Panin. Mesoscopic regularities of plastic deformation and fracture of coated and surface-hardened materials // Fizicheskaya mezomekhanika. 2004, v. 7, N special 1, p. 109-112 (in Russian).

7. M.H. Serror. Analytical study for deformability of laminated sheet metal // Journal of Advanced Research. 2013, v. 4, p. 83-92.

8. S. Das, A.T. Morales, A.R. Riahi, X. Mengburany, and A.T. Alpas. Role of Plastic Deformation on Elevated Temperature Tribological Behavior of an AlMg Alloy (AA5083), A Friction Mapping Approach // Metallurgical and Materials Transactions A. 2011, v. 42A, issue 8, p. 2384-2401.

9. T. Tokunaga, K. Matsuura, M. Ohno. Superplastic behavior of Al-coated Mg alloy sheet // Journal of Alloys and Compounds. 2014, v. 601, p. 179-185.

10. O.A. Gali, A.R. Riahi, A.T. Alpas. The effect of surface conditions on the elevated temperature sliding contact deformation of AA5083 alloy // Wear. 2015, v. 330-331, p. 309-319.
11. A.M. Zaharov. Industrial alloys of non-ferrous metals. Phase composition and structural components. M.: "Metallurgy", 1980.

12. V.P. Poida, V.V. Bryukhovetsky, A.V. Poida, R.I. Kuznetsova, A.P. Kryshtal', and Yu.Yu. Portash. Superplasticity in AK4-1ch Alloy at High Homological Temperatures // Metallofiz. Noveishie Tekhnol. 2009, v. 31, p. 1385-1398 (in Russian).

13. T.G. Langdon. A unified approach to grain boundary sliding in creep and superplasticity // Acta Metall. Mater. 1994, v. 42, issue 7, p. 2437-2443.

14. W.J.D. Shaw. Mikrosuperplastic behavior // Mater. Lett. 1985, v. 4, N 1, p. 1-4.

15. A.V. Poyda, V.V. Bryukhovetskiy, D.L. Voronov, R.I. Kuznetsova, V.F. Klepikov. Superplastic behavior of AMg6 alloy at high homological temperatures // Metallofiz. Noveyshiye Tekhnol. 2005, v. 27, N 3, p. 319-333 (in Russian).

16. G. Dirras. Filament formation during elevated temperature deformation of high purity ultrafine-grained aluminum // Materials Letters. 2010, v. 64, p. 11631165 .

17. J.H. Robinson, M.A. Rust, R.I. Todd. Mechanisms of microsuperplasticity // Materials Science Forum. 2007, v. 551-552, p. 135-145.

18. C.L. Chen, M.J. Tan. Cavity growth and filament formation of superplastically deformed Al 7475 alloy // Mater. Sci. and Eng. A. 2001, v. 298, N 1-2, p. 235-244.

19. W.D. Cao, X.P. Lu, H. Conrad. Whisker formation and the mechanism of superplastic deformation // Acta Mater. 1996, v. 44, N 2, p. 697-706.

20. V.P. Poyda, V.V. Bryukhovetskiy, R.I. Kuznetsova, A.V. Poyda, V.F. Klepikov. Formation and development of fibrous formations during superplastic deformation of matrix aluminum alloys // Metallofiz. Noveyshiye Tekhnol. 2003, v. 25, N 1, p. 117-132 (in Russian).

21. V.P. Poida, V.V. Bryukhovetskii, A.V. Poida, R.I. Kuznetsova, V.F. Klepikov, D.L. Voronov. Morphology and mechanisms of the formation of fiber structures upon high-temperature superplastic deformation of aluminum alloys // Fiz. Met. Metalloved. 2007, v. 103, N 4, p. 433-444 (in Russian).

22. V.V. Bryukhovetskii, V.P. Poida, R.I. Kuznetsova, V.F. Klepikov, and A.V. Poida. Superplastic Properties of Aluminum-Lithium Alloy 1421 at High Homological Temperatures // Phys. Met. Metallogr. 2002, v. 94 , p. $520-528$.

23. V.V. Bryukhovetsky, A.V. Poyda, V.P. Poyda, D.E. Milaya. Superplastic behavior of 1933 aluminum alloy with bimodal structure at elevated temperatures // Problems of Atomic Science and Technology. Series "Physics of Radiation Effect and Radiation Materials Science”. 2018, N 2 (114), p. 94-102.

24. R.Z. Valiev, I.V. Alexandrov. Bulk nanostructured metallic materials: production, structure and properties. M.: “Academic Book”, 2007. 


\title{
СВЕРХПЛАСТИЧЕСКАЯ ДЕФОРМАЦИЯ СПЛАВА АК4-1 С ПОВЕРХНОСТНЫМ СЛОЕМ, ПЕРЕПЛАВЛЕННЫМ ИМПУЛЬСНЫМ ПУЧКОМ ЭЛЕКТРОНОВ
}

\author{
В.В. Брюховецкий, А.В. Пойда, В.П. Пойда, Д.Е. Милая
}

Образцы алюминиевого сплава АК4-1, предварительно облученные импульсным пучком электронов, были продеформированы в условиях сверхпластичности. Изучены особенности структурных изменений в ходе сверхпластической деформации предварительно облученных образцов. Показано, что деформационные процессы, происходящие в основной части образца и в переплавленном импульсным пучком электронов слое, имеют принципиальные различия.

\section{НАДПЛАСТИЧНА ДЕФОРМАЦІЯ СПЛАВУ АК4-1 3 ПОВЕРХНЕВИМ ШАРОМ, ПЕРЕПЛАВЛЕНИМ ІМПУЛЬСНИМ ПУЧКОМ ЕЛЕКТРОНІВ}

\section{В.В. Брюховецький, А.В. Пойда, В.П. Пойда, Д.С. Мила}

Зразки алюмінієвого сплаву АК4-1, попередньо опромінені імпульсним пучком електронів, були продеформовані в умовах надпластичності. Вивчено особливості структурних змін у ході надпластичної деформації попередньо опромінених зразків. Показано, що деформаційні процеси, що відбуваються в основній частині зразка і в переплавленому імпульсним пучком електронів шарі, мають принципові відмінності. 